\title{
A potential global surveillance tool for effective, low-cost sampling of invasive Aedes mosquito eggs from tyres using adhesive tape
}

\author{
Thom Dallimore, David Goodson, Sven Batke and Clare Strode*
}

\begin{abstract}
Background: The international movement of used tyres is a major factor responsible for global introductions of Aedes invasive mosquitoes (AIMs) (Diptera: Culicidae) that are major disease vectors (e.g. dengue, Zika, chikungunya and yellow fever). Surveillance methods are restricted by expense, availability and efficiency to detect all life stages. Currently, no tested method exists to screen imported used tyres for eggs in diapause, the life stage most at risk from accidental introduction. Here we test the efficiency of adhesive tape as an affordable and readily available material to screen tyres for eggs, testing its effect on hatch rate, larval development, DNA amplification and structural damage on the egg surface.

Results: We demonstrated that the properties of adhesive tape can influence pick up of dormant eggs attached to dry surfaces. Tapes with high levels of adhesion, such as duct tape, removed eggs with high levels of efficiency ( $97 \% \pm 3.14)$. Egg numbers collected from cleaned used tyres were found to explain larval hatch rate success well, particularly in subsequent larval to adult emergence experiments. The strength of this relationship decreased when we tested dirty tyres. Damage to the exochorion was observed following scanning electron microscopy (SEM), possibly resulting in the high variance in the observed model. We found that five days was the optimal time for eggs to remain on all tested tapes for maximum return on hatch rate success. Tape type did not inhibit amplification of DNA of eggs from three, five or ten days of exposure. Using this DNA, genotyping of AlMs was possible using species-specific markers.
\end{abstract}

Conclusions: We demonstrated for the first time that adhesive tapes are effective at removing AlM eggs from tyres. We propose that this method could be a standardised tool for surveillance to provide public health authorities and researchers with an additional method to screen tyre cargo. We provide a screening protocol for this purpose. This method has a global applicability and in turn can lead to increased predictability of introductions and improve screening methods at high risk entry points.

Keywords: Aedes aegypti, Aedes albopictus, AlMs, Mosquito, Surveillance, Eggs, Tyres, Dengue, Zika

*Correspondence: Strodecl@edgehill.ac.uk Department of Biology, Edge Hill University, St. Helens Road, Ormskirk, Lancashire L39 4QP, UK

\begin{abstract}
Background
The spread of RNA based flaviviruses and alphaviruses such as dengue (DENV), yellow fever, Zika (ZIKV) and chikungunya viruses (CHIKV) have become a major global concern. Annual infection rates of DENV (family Flaviviridae) have been predicted at 284-528 million [1], resulting in $\sim 20,000$ reported deaths per year [2]. It is a
\end{abstract}


multi-form disease with varying side effects and severity, symptoms range from flu-like fevers and a characteristic skin rash, to severe haemorrhagic bleeding and potentially fatal hypertension. Some $30-54.7 \%$ (2.05-3.74 billion) of the world's population is now believed to be at risk from infection across 128 countries [3] with little substantial progress being made in reducing the spread of both the vectors and the disease. ZIKV (family Flaviviridae) has also become well reported with 440,0001,300,000 reported cases from the 2015 Brazil epidemic alone [4] and can be asymptomatic or present as mild flulike symptoms concurrent with some DENV manifestations. ZIKV can also spread via intrauterine transmission leading to congenital microcephaly in unborn children [4-6], as well as Guillain-Barré syndrome [7]. Phylogenetic analysis of whole ZIKV genomes suggests the disease originated in East Africa in the 1920's [8] and until recent pandemics across the Pacific and the Americas, had a fairly slow epidemiology [9]. Reasons for accelerated ZIKV are yet to be confirmed but are likely to be multi-causal with lack of localised immunity, increased mobility of competent vectors, delayed detection and expanding levels of globalisation the likely candidates $[10$, $11]$.

The primary vectors of these arboviruses are Aedes (Stegomyia) aegypti (L.) (yellow fever mosquito) and Aedes (Stegomyia) albopictus (Skuse) (Asian tiger mosquito). Both species have immature aquatic stages that require natural water-filled tree holes, bamboo nodes and leaf axels for egg and larval development but have also become successfully adapted to living in proximity to humans by utilising human made water-filled containers and subterranean drainage systems as viable alternatives [12-14].

The global spread of these species is associated with the transportation of human goods such as the international trade in tyres and "wet footed" plants, such as lucky bamboo [15-18]. Aedes aegypti and Ae. albopictus have biological characteristics that, to differing extents, favour invasiveness. Both have developed anthropophilic adaptive tendencies, resulting in their proximity to humans for all aspects of their life-cycle and feed primarily on human blood [19, 20]. One such adaptation includes the use of manmade containers. Aedes aegypti deposits $85-125$ eggs [21] on the margins of small temporary pools that form within these containers where they utilise a process of diapause, an adaptation to allow maximum return for larval development in small water bodies that can quickly evaporate [22-24]. Oviposition technique is an integral part of this trait, with eggs being placed directly adjacent to the meniscus where a secretion on the exochorion adheres the egg ventrally to the material margin of the pool $[25,26]$. This prevents eggs from falling into the water body and allows repeated submergence over several flooding cycles resulting in staggered larval emergence, also referred to as instalment hatching. After egg laying, a drying period of $11-13 \mathrm{~h}$ is required for the development of the serosal cuticle (SC), an inner membrane of the egg-shell that allows the embryo to survive desiccation [23]. In captive bred populations of $A e$. aegypti, eggs have been reported as surviving such periods for 6-12 months depending on environmental conditions (J. Longbottom, pers. comm.). These adaptations allow aedine eggs to survive long journeys attached to the surface of vessels whilst remaining in a state of diapause. This key physiological feature has allowed for the colonisation of new territories from their ancestral origin of sub-Saharan Africa [27].

Global modelling of aedine species distribution suggest that the range of both Ae. aegypti and Ae. albopictus is still expanding, this has been particularly well recorded across European and American continents [28]. In Europe, the movement of Ae. albopictus has led to the first documented cases of autochthonous transmission of CHIKV and DENV [29] and reports of Ae. aegypti well beyond its expected range [30]. Aligned with recently recorded adaptive behaviour of AIMs [14, 31], this presents an argument for greater surveillance at the current limits of their geographical distribution [15].

The movement of AIMs appears to be multi-causal, but primarily through human transport networks. Active dispersal of these species is considered to be limited with a reported life-time mean mobility of approximately 50-363 m [32-34]. Recent evidence suggests that adults can also be passively dispersed by cars [35], the detection of Ae. albopictus in motorway service stations in Kent, England [36] and Bavaria and Baden-Wuerttemberg, Germany [37], supports this theory. However, the global movement of car tyres has been highlighted as a primary method of distributing Ae. albopictus and Ae. aegypti $[38,39]$. It was by this method that Ae. aegypti was introduced into the Netherlands from Florida, USA, in 2010 [15].

To combat the further spread of AIMs international efforts have been made to increase surveillance at major ports and airports, tyre yards and service stations, as well as areas of suitable habitation [40-46].

Traditional surveillance techniques for AIMs mostly utilise oviposition-based traps, larval dipping and attractants such as $\mathrm{CO}_{2}$, pheromones, light and human bait [41]. The efficiency of such traps is well documented [47]. However, the deployment of different sampling methods between surveillance programmes is highly variable at an international and national scale, possibly a reflection of resource availability, as well as the varying inclination of local and national authorities to promote active 
surveillance [48]. These techniques have been fruitful in locating AIMs, however, these methods target larvae, pupae, adults and in situ egg deposition. Dormant eggs attached to the surface of car tyres, or dry containers are overlooked [15, 49]. In surveillance systems where port authority screening is relied upon as the first line of defence against AIMs, any cargo containing eggs passes freely without discovery. Additionally, current surveillance requires the presence of active females in various reproductive states. Oviposition trapping techniques rely on recently introduced females to blood feed, or to have been introduced in a gravid state. Likewise, $\mathrm{CO}_{2}$ and pheromone attractants require mosquitoes to be actively seeking a blood source. Such surveillance methods target adult mosquitoes that are attempting, or even succeeded, in reproducing. These methods can reduce response times for post-discovery control and often bypass populations of Aedes eggs being transported in a desiccated state that later emerge, when wetted, into a new territory. In this instance, early detection may only occur in countries with robust surveillance, or by chance reports of nuisance biting.

Although there is no singularly effective method of surveillance for AIMs it is essential that a range of sampling tools are available to determine their presence, to quantify the extent of any infestation and to provide accurate species identification and rapid initiation of control measures.

To develop a low cost and easy to use tool for mosquito workers to standardise screening of car tyres for Aedes eggs, we tested the efficacy of four distinct types of sticky tape for their ability to remove the mosquito eggs from the tyre surface. Additionally, we investigated the post-removal impact of this technique on the ability to (i) rear the sampled eggs to larvae and adulthood for identification and whether time exposed to the tape had any negative effects; (ii) identify the eggs by morphology and for possible damage, using SEM; and to (iii) investigate whether the tape types had any notable effect on DNA integrity by genotyping extracted eggs using species specific markers.

\section{Methods}

\section{Maintenance of colonies}

Aedes aegypti (New Orleans strain) laboratory colonies were reared within the Edge Hill University Vector Biology Research Group insectaries at $27^{\circ} \mathrm{C}$ and $70 \% \mathrm{RH}$, on an $11 \mathrm{~h}$ day/night cycle with a simulated $60 \mathrm{~min}$ dawn/ dusk period, using a lighting system of $4 \times$ Osram Dulux 26W 840 lights positioned approximately $2 \mathrm{~m}$ from the rearing cages. Several hundred eggs ( 1000-1500) deposited on filter paper were stimulated to hatch by submerging filter papers in a broth of $0.1 \mathrm{~g}$ brewer's yeast
(Holland \& Barrett, Ormskirk, UK) and $0.5 \mathrm{~g}$ of nutrient broth (Sigma-Aldrich, Dorset, UK) dissolved in $1.4 \mathrm{l}$ of $\mathrm{dH}_{2} \mathrm{O}$ [50]. Of those successfully hatched ( 500-1000), first- and second-instar larvae were separated into 4 or 5 separate trays to avoid overcrowding and fed using ground fish flakes (Aquarian Tropical Fish Food, UK), $\sim 0.08 \mathrm{mg}$ per larvae after hatching with volumes doubled for each day there after until pupation. All fourth-instar larvae and pupae were then transferred into $30 \times 30 \times$ $30 \mathrm{~cm}$ insect rearing cages (\#211261, BugDorm-1. NHBS, Totnes, UK) and emergent adults fed for the first three days on $10 \%$ sugar solution soaked into cotton wool. Emergent male and female mosquitoes were allowed to mix for a minimum of three days to ensure that most females had the opportunity to copulate. After three days, all females ( 400-500) were removed and placed into separate rearing cages and starved for $24 \mathrm{~h}$ prior to blood-feeding. All females were engorged on defibrinated horse blood (Thermo Fisher Scientific, Altrincham, UK) using the Hemotek ${ }^{\circledR}$ membrane feeding system (Hemotek Ltd, Blackburn, UK) until fully distended and then left for $24 \mathrm{~h}$ with a supplement of $10 \%$ sugar solution until gravid. Any gravid females were then separated into two equal batches; the first batch was used within experimental treatments $(\sim 200)$ and the second batch for rearing the next generation $(\sim 200)$. Specimens used during experimentation did not exceed more than three generations to reduce possible effects of inbreeding depression on egg viability [51].

\section{Egg laying on car tyres}

Two used car tyres (175/70 R13, Michelin, UK) were obtained from an outdoor store at a farmyard in Burscough, Lancashire and each divided into eight equal sections. A first batch of eight sections were scrubbed with a detergent, sterilised with bleach and thoroughly rinsed using $\mathrm{dH}_{2} \mathrm{O}$ to ensure no residual contaminants were present (hereafter referred to as 'clean'). A further eight were left in the condition they were found in (hereafter referred to as 'dirty'). Each section was $\sim 21$ (L) $\times$ $17(\mathrm{~W}) \times 13(\mathrm{H}) \mathrm{cm}$ in size, just large enough to move in and out of bugdorms without dislodging or disturbing in situ eggs. Four tyre sections were used per round of egg laying with a total of 16 replicates/tape type/treatment (treatment $=$ no. of days exposed to the tape). For each replicate, a section of car tyre was added to each rearing cage along with 20 gravid females and $75 \mathrm{ml}$ of $\mathrm{dH}_{2} \mathrm{O}$ deposited into the centre of each tyre section to create a small pool in the central depression. The aim here was to encourage female oviposition and egg adherence around the margin (Fig. 1). Females were left for $72 \mathrm{~h}$ to lay eggs and then removed by aspiration. The remaining $\mathrm{dH}_{2} \mathrm{O}$ was drawn from each tyre by pipetting to prevent 


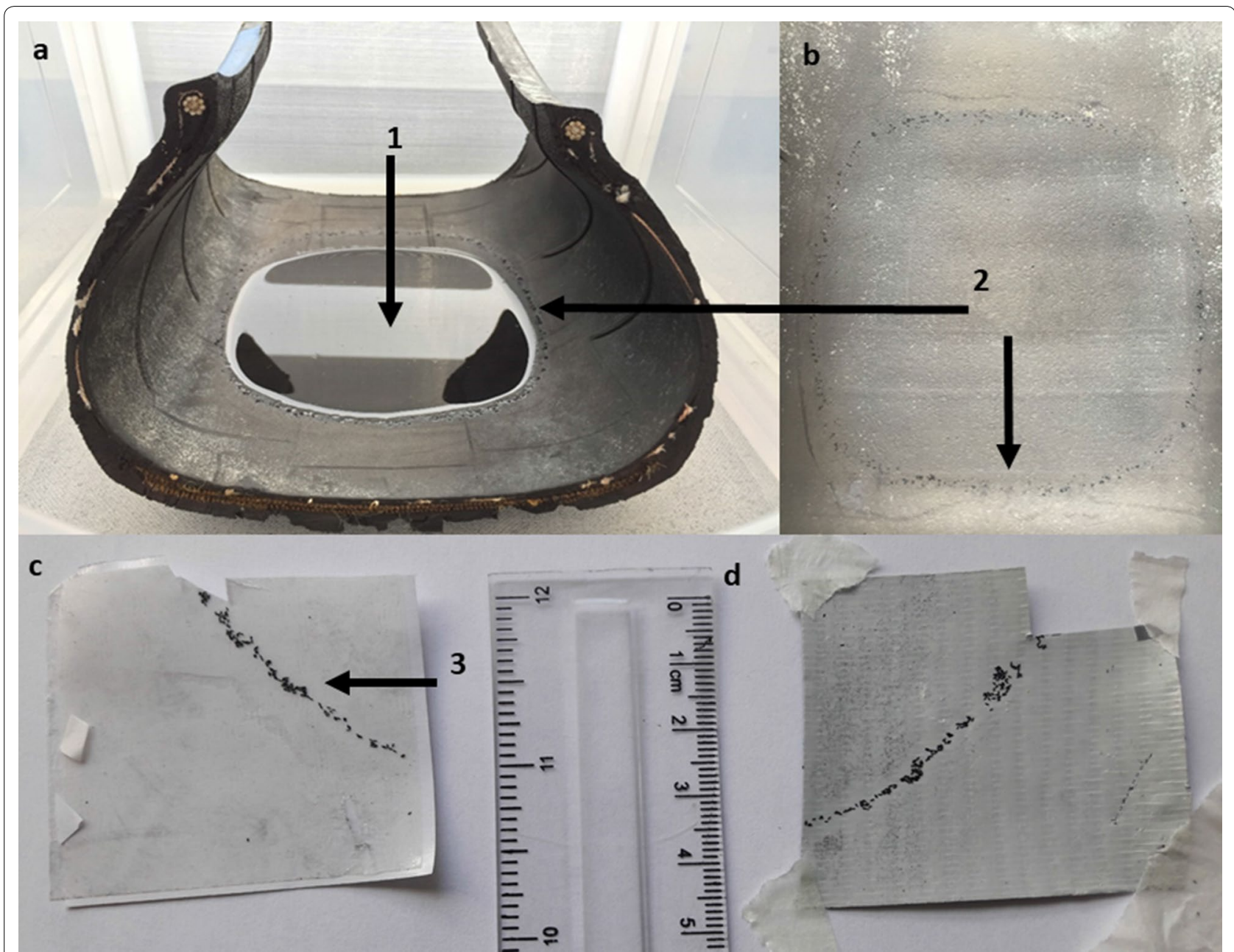

Fig. 1 Visibility of Ae. aegypti egg deposition on tyre and tape sections. a Section of tyre placed within a bugdorm. $\mathbf{b}$ Dorsal view of the tyre after drying. c After sampling, eggs attached to adhesive surface of double-sided carpet tape. $\mathbf{d}$ After sampling, eggs attached to adhesive surface of duct tape. (1) $75 \mathrm{ml}$ of $\mathrm{dH}_{2} \mathrm{O}$ added to the tyre to encourage oviposition. (2) The deposited eggs can be seen by the naked eye as a dark speckled ring around the margin of the reservoir. (3) Increased visibility of eggs on adhesive tape after sampling

dislodging the eggs and ensure that they were not stimulated to hatch. Tyre sections were then removed from the bugdorm and allowed to dry at room temperature for 24 h.

\section{Egg sampling/larval rearing with sticky tape}

Four tape types were selected based on different properties (summarised in Table 1). Each tape type was cut into a $50 \mathrm{~mm}^{2}$ sections and applied to the tyre along the line of deposited eggs, using a stratified random sampling method and adhered with gentle pressure from the tip of the index finger. Tape application was carried out by the same two individuals to reduce possible user bias. The outline of each piece of tape was marked using white chalk. Each tyre section accommodated $8 \times$ $50 \mathrm{~mm}^{2}$ pieces of tape allowing for two replicates of each tape type per tyre section. The tape was removed using fine tipped entomological forceps and placed into a dry $250 \mathrm{ml}$ glass beaker and counted under stereomicroscope (Leica M80, GT vision, Suffolk, UK) at $40 \times$ magnification, along with any remaining eggs within the marked areas on the tyre.

Three egg exposure treatments of three, five- and tenday intervals were undertaken to determine if the tapes had any effect on hatch rate success. After the allotted exposure time, the egg-laden tapes were submerged in $100 \mathrm{ml}$ of hatching broth in a $250 \mathrm{ml}$ beaker. Emergent larvae were counted after $24 \mathrm{~h}$ and transferred into beakers with $100 \mathrm{ml}$ of $\mathrm{dH}_{2} 0$ and reared as described above. A laboratory control was also established whereby the same number of gravid females were encouraged lay on filter paper and put through the same treatments as applied to the different tape types. 
Table 1 Properties of adhesive tapes used during experimentation

\begin{tabular}{|c|c|c|c|}
\hline Tape type & Code & Properties & Cost \\
\hline Body tape & BT & $\begin{array}{l}\text { Medium levels of adhesion. Less commercially available } \\
\text { but contains less chemicals that potentially have less } \\
\text { deleterious effects on egg viability }\end{array}$ & $\begin{array}{l}£ 4.90 \text { for } 27 \text { strips (Eylure Body Tape Pre-Cut Adhesive } \\
\text { Strips, Boots UK, Ormskirk, England) }\end{array}$ \\
\hline Clear packing tape & PT & $\begin{array}{l}\text { Low-medium levels of adhesion, wide commercial } \\
\text { availability, low cost, may be less damaging to eggs } \\
\text { during transfer }\end{array}$ & $\begin{array}{l}\text { £3.28 for (L) } 100 \mathrm{M}(\mathrm{W}) 50 \mathrm{~mm} \text { (Diall Clear Packing Tape, } \\
\text { B\&Q, Aintree, England) }\end{array}$ \\
\hline Double-sided flooring tape & $\mathrm{CT}$ & $\begin{array}{l}\text { Medium-high levels of adhesion. Widely available in DIY } \\
\text { stores, double-sidedness may prove advantageous for } \\
\text { adhering samples for transportation }\end{array}$ & $\begin{array}{l}£ 8.90 \text { for (L) } 25 \text { M (W)50 mm (Diall White Double Sided } \\
\text { Tape, B\&Q, Aintree, England) }\end{array}$ \\
\hline Duct tape & DT & $\begin{array}{l}\text { High levels of adhesion, wide commercial availability, } \\
\text { a white background to improve visibility, easily torn } \\
\text { without the need for cutting apparatus }\end{array}$ & $\begin{array}{l}\text { £ } 2.70 \text { for }(\mathrm{L}) 5 \mathrm{M}(\mathrm{W}) 50 \mathrm{~mm} \text { (Duck Tape }{ }^{\circledR}, \mathrm{B} \& \mathrm{Q}, \text { Aintree, } \\
\quad \text { England) }\end{array}$ \\
\hline
\end{tabular}

After the first $24 \mathrm{~h}$ of submergence, tapes were removed and dried at room temperature for $48 \mathrm{~h}$ and re-submerged for a second time. Larvae were once again removed and counted after $24 \mathrm{~h}$. All larvae were left to develop into adults and numbers recorded to determine if tape exposure effected later development.

\section{Scanning electron microscopy (SEM)}

A descriptive approach was used to observe potential damage to the egg morphology caused by the removal of eggs using tape by making observations through scanning electron microscopy (6010LV, JEOL (UK) Ltd., Herts, UK). Sections $\left(10 \mathrm{~mm}^{2}\right)$ of egg loaded tape of each type and treatment, plus controls, was cut away and attached to $12.5 \mathrm{~mm}$ SEM stubs using carbon tabs (Agar Scientific Ltd., Essex, UK). Samples were then coated in gold for 4 min $(\sim 4 \mathrm{~nm})$ using a sputter coater (Q150R ES, Quorum Technologies Ltd., East Sussex, UK). Eggs were left in situ throughout this process. Samples were viewed in high vacuum mode where accelerated voltage $=10 \mathrm{kV}, \mathrm{WD}=$ 12 and spot size $=50$.

\section{Molecular methods: PCR-based identification}

Additional checks were made do determine if amplification of egg DNA was still possible after three, five and ten days attached to the different tape types. A subsample (10 $\mathrm{mm}^{2}$ squares) from each tape type, exposure and treatment were removed from egg-loaded tapes and placed into individual $1.5 \mathrm{ml}$ tubes and stored at $-20{ }^{\circ} \mathrm{C}$ until extraction. The number of eggs in each subsample ranged from 2 to 16. Each sample was homogenised (including the tape) for $30 \mathrm{~s}$ whilst dry using an electronic pestle and mortar (431-0094, VWR, Leicestershire, UK), $180 \mu \mathrm{l}$ of buffer ATL and $20 \mu \mathrm{l}$ of proteinase K (Qiagen, Manchester, UK) was added and homogenised for several seconds. Samples were thoroughly vortexed and left to lyses on an orbital shaker at $56{ }^{\circ} \mathrm{C}$ for $15 \mathrm{~h}$ after which when the remaining pieces of tape were removed from each sample and discarded. DNA extraction was completed using the DNeasey ${ }^{\circledR}$ Blood and Tissue Spin Column Kit (Part no. 69506, Qiagen, Manchester, UK) following the provided protocol, with $50 \mu \mathrm{l}$ elution buffer held in the columns for $5 \mathrm{~min}$ and passed through the column twice to increase DNA yield. To test amplification, a polymerase chain reaction (PCR)-based analyses was carried out using species-specific primers developed by Das et al. [52] and Higa et al. [53] (Table 2).

Each $25 \mu \mathrm{l}$ PCR reaction for the Das et al. [52] primers consisted of 2.5-20 ng of DNA template, $0.5 \mathrm{U}$ of Phusion ${ }^{\circledR}$ High-Fidelity Polymerase (New England Biolabs ${ }^{\circledR}$ Ltd. Herts, UK), $1 \times$ Phusion HF Buffer (NEB), $200 \mu \mathrm{m}$ of dNTP mix (NEB), $0.5 \mu \mathrm{M}$ of primers AUF and AUR and $0.7 \mu \mathrm{M}$ of AEG and $2 \%$ DMSO (NEB). PCR amplification was performed using a Primer Thermal Cycler (Techne, Staffordshire, UK) programmed with an initial denaturation of $98{ }^{\circ} \mathrm{C}$ for $30 \mathrm{~s}$, followed by 35 cycles of 98 ${ }^{\circ} \mathrm{C}$ for $10 \mathrm{~s}$ (denaturation), $59{ }^{\circ} \mathrm{C}$ for $20 \mathrm{~s}$ (annealing), 72 ${ }^{\circ} \mathrm{C}$ for $20 \mathrm{~s}$ (extension), followed by a final extension of 72 ${ }^{\circ} \mathrm{C}$ for $7 \mathrm{~min}$. Each $25 \mu \mathrm{l}$ PCR reaction for the Higa et al. [53] primers consisted of 2.5-20 ng of template, $0.5 \mathrm{U}$ of Phusion ${ }^{\circledR}$ HF Polymerase, $1 \times$ Phusion HF Buffer, 200 $\mu \mathrm{m}$ of dNTP mix, $0.5 \mu \mathrm{M}$ of primers 18 SFHIN and CP16 and $0.7 \mu \mathrm{M}$ of aeg.r1. Thermal cycler setting as outlined above, but with an annealing temperature of $70{ }^{\circ} \mathrm{C}$. PCR products were resolved on a $2 \%$ agarose/ethidium bromide gel with HyperLadder ${ }^{\mathrm{TM}} 100 \mathrm{bp}$ (Bioline Reagents Ltd, London).

\section{Analysis}

A comparison of the egg pick-up efficiency of the different tape types was carried out using a Kruskal-Wallis test, after a Shapiro-Wilks test showed that the data were non-parametric. Multiple comparisons between tape types for the egg pick-up efficiency was investigated using the Nemenyi post-hoc test. 
To test how the number of larvae and adults was affected by the number of eggs and larvae, respectively and in regard to different tape types and egg exposure time to the tape (i.e. 3, 5 and 10 days), mixed effect models were used. We selected the best-fit model using Akaike's information criterion (AIC) and from there we calculated total explained variance for each fixed and random effect term. In addition, we used linear models to investigate individual tape treatments and to test the correlations between the number of eggs picked up and larval hatch rate and number of larvae and emergent adults. A Shapiro-Wilks test showed that the hatch rate and adult emergence data were non-parametric, henceforth we square root transformed the data before running the linear models. To account for differences in the starting number of eggs and larvae for each sample, we weighted the transformed data proportionately by the total number of adults in the population and accounted for differences of larval success from the previous treatments as follows:

$$
\text { weight }=\left(\left(\frac{A_{1}}{\sum A_{\text {Total }}}\right) A_{1+2}-L_{1+2}\right)-1
$$

where $A_{1}$ is the number of adults in a sample following the first emergence, $A_{\text {Total }}$ is the total number of adults in the population, $\mathrm{A}_{1+2}$ is the number of adults in a sample following first and second emergence and $L_{1+2}$ is the number of larvae in a sample following first and second hatching. Analyses was carried out using RStudio v.3.4.1.

\section{Results}

Within the parameters of the experiment 41,337 eggs were laid in total and across all tyre replicates (eggs, $n$ $=29,170$ ) and filter paper controls (eggs, $n=12,167$ ). A total of $25,670(88 \%)$ eggs were picked up by all tape type replicates, 11,056 (43.07\%) of tape treatments and 7771 (63.87\%) of controls developed into first-instar larvae during first submergence. The second submergence produced 1469 (5.04\%) larvae from tape treatments and 61 (0.55\%) from controls, 10,808 (51.06\%) first submergence eggs successfully hatched from clean tyres replicates,
1033 (4.88\%) from second submergence. A considerably lower hatch-rate was recorded for samples collected from dirty tyres; 248 (5.51\%) of first submergence eggs were hatched and 436 (9.68\%) from the second submergence (Table 3). Analysis of the egg pick-up efficiency using a Kruskal-Wallis test showed significant differences between the efficiency of tape types $\left(\chi^{2}=114.52\right.$, $d f=3, P<0.0001)$. Further exploration of the data using a post-hoc Nemenyi test demonstrated that the difference in pick-up efficiency was between the PT and all other tapes. There were no statistically significant differences between all other treatments (Table 4). Notably, the egg pick-up efficiency of DT, BT and CT showed high levels of egg pick up efficiency (>96\%) and relatively low levels of variation $(\mathrm{s}=3.14-1.39)$ compared to that of $\mathrm{PT}$ $(55.18 \%, \mathrm{~s}=22.19)$ (Fig. 2).

\section{The effect of tape type on hatch-rate success and adult emergence}

To test if the number of eggs picked up can be used to explain the number of larvae hatching and whether the number of larvae hatching can explain the number of emergent adults between the different tape types and days of exposure, two approaches were used. In the case of hatch rate success (i.e. the transition from eggs picked up to hatched larvae) the best-fit mixed effect model $\left(R^{2}\right.$ $=0.77$ ) included number of larvae and time of exposure as a fixed and tape type as a random factor (Tables 5, 6). Similarly, in the case of adult emergence (i.e. the transition of hatched larvae to adult) the best-fit mixed effect model $\left(R^{2}=0.99\right)$ included number of larvae and time of exposure as a fixed and tape type as a random factor (Tables 5,6$)$. In both models, most of the variance was explained by the number of eggs $\left(R^{2}=0.64\right)$ or the number of larvae $\left(R^{2}=0.97\right.$, Table 6$)$. This was followed by tape type and exposure (Table 6). To investigate the effect of individual tape types a linear model was fitted for each treatment combination (Fig. 3, Tables 7, 8). The results indicated that the number of larvae that hatch is a good indicator of the number of adults that will emerge (Table 5). All treatments fell close to the 1:1 line, except

Table 2 Species-specific PCR primers for the identification of Ae. aegypti

\begin{tabular}{llll}
\hline Species & Primer code & Sequence (5'-3) & Reference \\
\hline Universal forward primer & AUF & TCAAAATTAAGGGTAGTGGT & {$[52]$} \\
Universal reverse primer & AUR & GACTTCAACTGGCTTGAACT & {$[52]$} \\
Ae. aegypti & AEG & GACACCGAGGCGCCCATTGC & {$[52]$} \\
Universal forward primer & 18 FHIN & GTAAGCTTCCTTTGTACACACCGCCCG & {$[53]$} \\
Universal reverse primer & CP16 & GCGGGTACCATGCTTAAATTAGGGGGTA & {$[53]$} \\
Ae. aegypti & aeg.r1 & TAACGGACACCGTTCTAGGCCCT & {$[53]$} \\
\hline
\end{tabular}




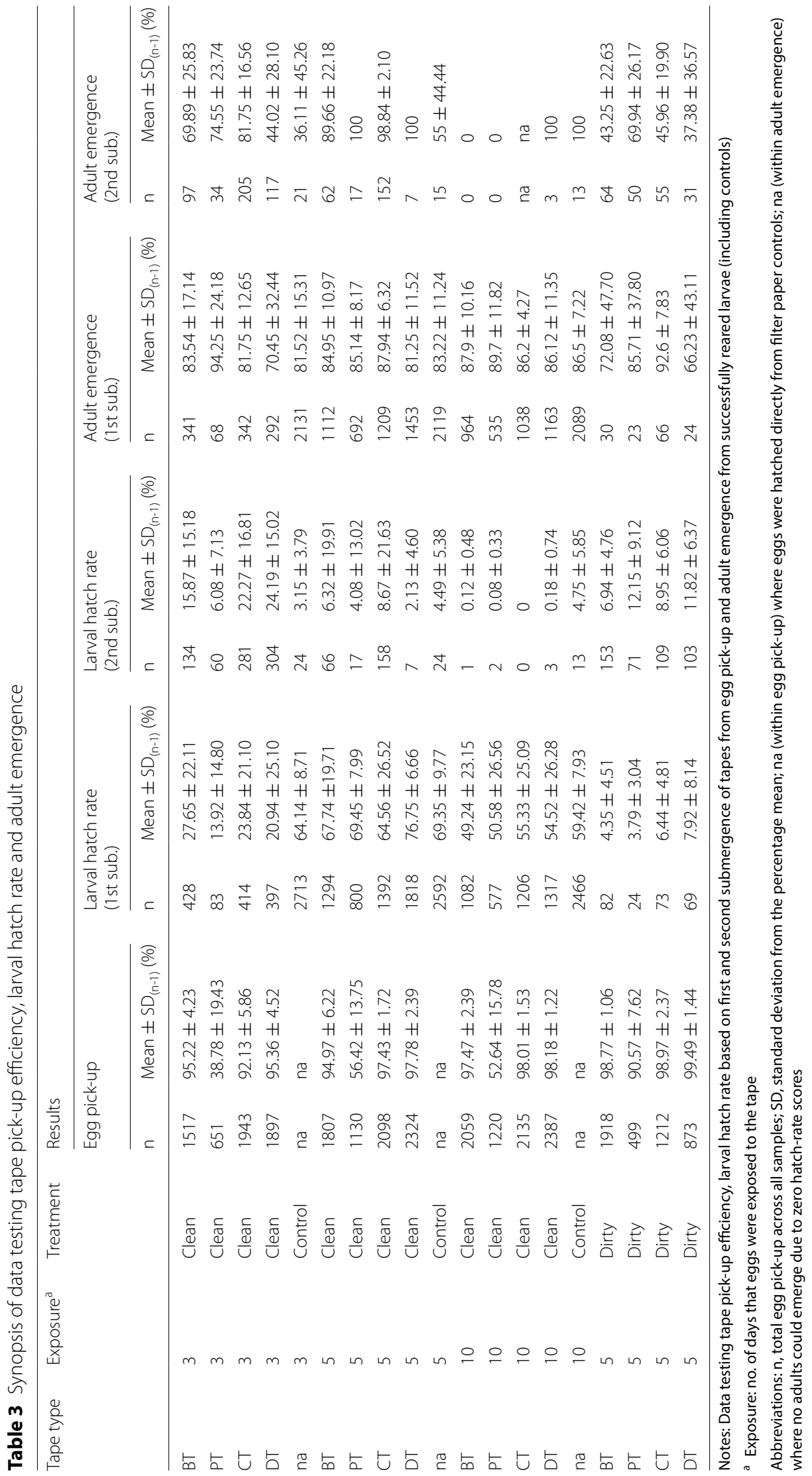


Table 4 Egg pick-up efficiency in different sticky tape treatments. Results of the Nemenyi post-hoc test following a Kruskal-Wallis test

\begin{tabular}{llllll}
\hline Tape type & Egg pick-up (\%) & \multicolumn{2}{l}{ Tape type } & & \\
\cline { 3 - 7 } & Mean \pm SD & BT & PT & FT & DT \\
\hline BT & $96.30 \pm 4.39$ & - & - & - & - \\
PT & $55.18 \pm 22.19$ & $5.2 \mathrm{e}-14$ & - & - & - \\
CT & $96.3 \pm 4.34$ & 1.00 & $4.9 \mathrm{e}-14$ & - & - \\
DT & $97.45 \pm 3.14$ & 0.54 & $3.6 \mathrm{e}-14$ & 0.59 & - \\
\hline
\end{tabular}

Abbreviation: SD, standard deviation

for BT and DT from the dirty tyres. Therefore, if eggs hatch, it is likely that they will make it to adulthood; however, the number of eggs less efficiently explained the number of successfully hatched larvae. Generally, the five-day treatment resulted in stronger correlations compared to the three- and ten-day treatments (Tables 7, 8, Fig. 3). Regardless of the length of exposure to the tapes, the dirty tape always resulted in poorer explanatory power of either emerged larvae number from egg number, or adult emergence number from larvae number.

\section{Cuticular condition and species identification by SEM}

Descriptive observations were made of the condition of the eggs in situ upon both the control and tape treatments using SEM revealing that most of the eggs removed from car tyres showed varying levels of damage to the exochorion (Fig. 4), but less so to the endochorionic and serosal cuticle [54]. Additionally, SEM micrographs demonstrate that identification of the mosquito eggs via morphology alone is unlikely to be possible using this sampling technique as only a dorsal perspective of the egg is visible after pick-up.

\section{Interference of DNA amplified from mosquito eggs}

DNA isolation from mosquito eggs following the use of tape produced DNA yields suitable for successful PCR amplification. Isolation from a single egg extracted from clear tape should produce enough yield to amplify species-specific markers that could be easily visualised with ethidium bromide gel electrophoresis. All treatments including from controls successfully amplified using the species-specific markers indicating that tape treatment does not inhibit amplification of DNA after a period of up to 10 days of exposure to tape types followed by storage at $-20{ }^{\circ} \mathrm{C}$

\section{Discussion}

\section{Identification of aedine species from eggs}

Adhesive tape has previously been used in the trapping of other adult insects $[55,56]$ and the application of adhesive tape to locate mosquito eggs is not unknown between entomologists working in the field, although it is only rarely reported in grey literature [41]. We find

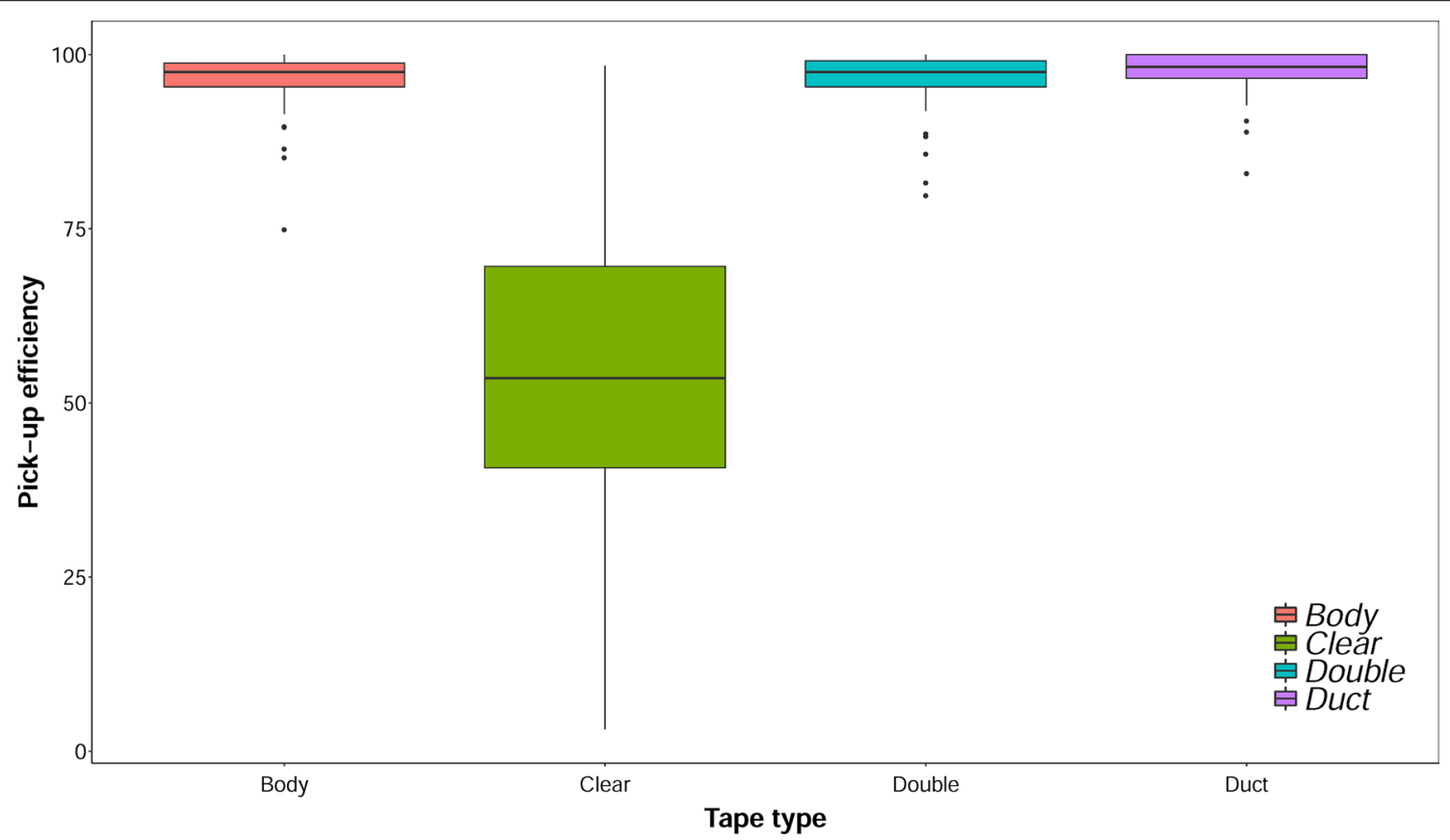

Fig. 2 Box plots with error bars of tape types vs percentage egg pick-up from the surface of clean tyres 
no validation of tape in surveillance or ecological studies of mosquito eggs. It is probable that the development of adhesive tapes for this purpose has been overlooked, as the identification of mosquito eggs to the species level was historically carried out by morphology, often difficult and required an elevated level of expertise with often ambiguous results. However, the recent increase in accessibility, doubled with reduced costing for technologies, such as matrix assisted laser desorption/ionization (MALDI-TOF) [57], scanning electron microscopy (SEM) [58] and genetic techniques such as species-specific markers [52, 53, 59], DNA barcoding $[60,61]$ and eDNA analysis [62], has eased the burden of egg identification. Rearing techniques for Aedes has also improved over the last 50 years with many publications providing a myriad of workable methodologies [50, 63-65].

The rapid development of such new species identification systems must be matched with a progressive approach to field sampling techniques. Surveillance for eggs is advantageous as it allows for a timelier response to introductions.

\section{Adhesive tape in Aedes surveillance}

Currently $50 \%$ of the world's population is at risk from DENV due to the presence of AIMs such as Ae. aegypti and Ae. albopictus. Aligned with this, the threat of autochthonous transmission of arbovirus diseases (e.g. DENV, CHIKV and ZIKV) in areas where such diseases are not endemic is becoming a serious public health issue [29, 66-70]. The international movement of AIMs is a serious threat to human health and it is vital that the scientific community and public bodies, develop
Table 6 Summary of the variance from the models that best explained eggs hatching and the numbers of larvae to adult emergence

\begin{tabular}{lllll}
\hline $\begin{array}{l}\text { Development } \\
\text { transition }\end{array}$ & Variable & Effect & $\begin{array}{l}\text { Explained } \\
\text { variance } \\
\left(\text { Adj. } R^{2}\right)\end{array}$ & $\begin{array}{l}\text { Unexplained } \\
\text { variance } \\
\left(\text { Adj. } R^{2}\right)\end{array}$ \\
\hline $\begin{array}{llll}\text { Egg to larvae emer- } \\
\text { gence }\end{array}$ & $\begin{array}{llll}\text { Total variance } \\
\text { No. of eggs }\end{array}$ & Fixed & 0.77 & 0.23 \\
& Tape type & Random & 0.42 & 0.36 \\
Larvae to adult & Exposure & Fixed & 0.14 & 0.86 \\
emergence & Total variance & & 0.99 & 0.01 \\
& No. of larvae & Fixed & 0.97 & 0.03 \\
& Tape type & Random & 0.43 & 0.57 \\
& Exposure & Fixed & 0.14 & 0.86 \\
\hline
\end{tabular}

Note: For each contributing variable (i.e. tape type and exposure) the explained and the unexplained are presented

novel methods of surveillance to increase efficiency. Here, we have demonstrated the value of adhesive tape as a method of improving surveillance by assisting in the identification of tyres that carry AIM eggs in diapause. Adhesive tape has a global availability and can be acquired inexpensively, making it a readily available material for use in tyre screening at any location around the world. However, the application of this method must be carefully considered before use in the field. Locating mosquito eggs via the application of adhesive tape is not a cause to assume that AIMs, or those with vector potential have been located. Eggs could be in fact from container-breeding, non-vector, species of mosquitoes.

Table 5 Mixed effect model results of number of eggs hatching and the numbers of larvae to adult emergence for the different tape types and exposure treatments

\begin{tabular}{|c|c|c|c|c|c|c|}
\hline Development transition & Model & Form & df & AIC & $\mathrm{BIC}$ & P-value \\
\hline \multirow[t]{6}{*}{ Egg to larvae emergence } & M1 & No. of larvae $\sim$ No. of eggs + Exposure + (Tape type) & 7 & 2635.1 & 2660.3 & $2.00 E-16^{* * *}$ \\
\hline & M2 & No. of larvae $\sim$ No. of eggs + Exposure & 6 & 2647.4 & 2669.0 & $2.00 \mathrm{E}-16^{* * *}$ \\
\hline & M3 & No. of larvae $\sim$ No. of eggs + (Tape type) & 4 & 2757.9 & 2772.3 & 1 \\
\hline & M4 & No. of larvae $\sim$ Exposure + (Tape type) & 6 & 2882.8 & 2904.4 & 1 \\
\hline & M5 & No. of larvae $\sim$ Tape type & 6 & 2908.8 & 2930.5 & 1 \\
\hline & M6 & No. of larvae $\sim$ Exposure & 5 & 3016.0 & 3034.1 & 1 \\
\hline \multirow[t]{6}{*}{ Larvae to adult emergence } & M7 & No. of adults $\sim$ No. of larvae + Exposure + (Tape type) & 7 & 684.3 & 709.5 & $2.00 \mathrm{E}-16^{* * *}$ \\
\hline & M8 & No. of adults $\sim$ No. of larvae + Exposure & 6 & 747.4 & 769.1 & $2.00 E-16^{* * *}$ \\
\hline & M9 & No. of adults $\sim$ No. of larvae + (Tape type) & 4 & 706.4 & 720.9 & 1 \\
\hline & M10 & No. of adults $\sim$ Exposure + (Tape type) & 6 & 2861.1 & 2882.7 & 1 \\
\hline & M11 & No. of adults Tape type & 5 & 2998.1 & 3016.1 & 1 \\
\hline & M12 & No. of adults $\sim$ Exposure & 5 & 2998.1 & 3016.1 & 1 \\
\hline
\end{tabular}

Note: The model with the lowest AIC (Akaike's information criterion) and BIC (Bayesian information criterion) was retained (i.e. the best-fit model) and Chi-square test was used to test for significance

${ }^{*} \mathrm{P}<0.05, * * \mathrm{P}<0.01,{ }^{* * * P}<0.001$ 

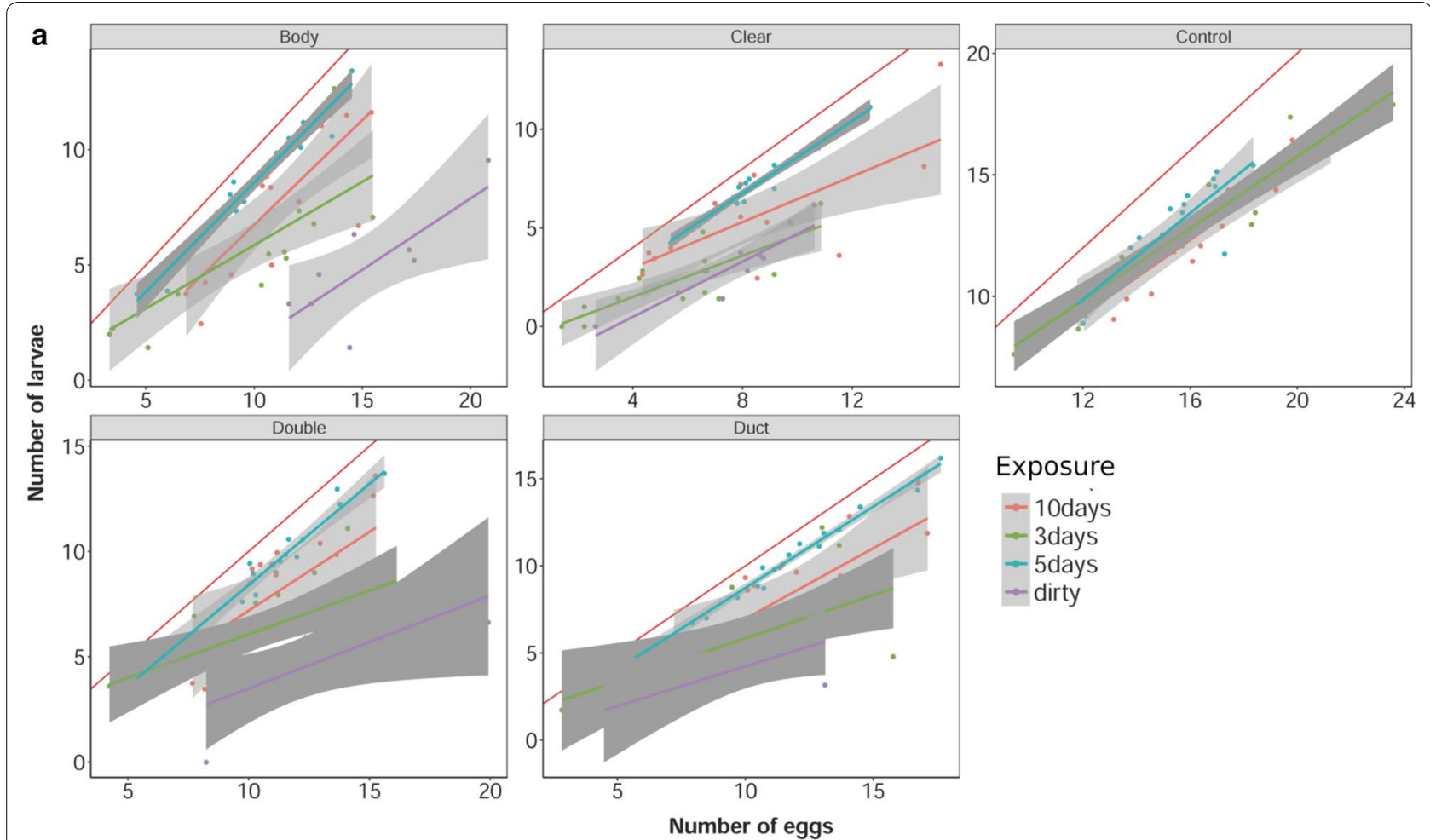

\section{Exposure}
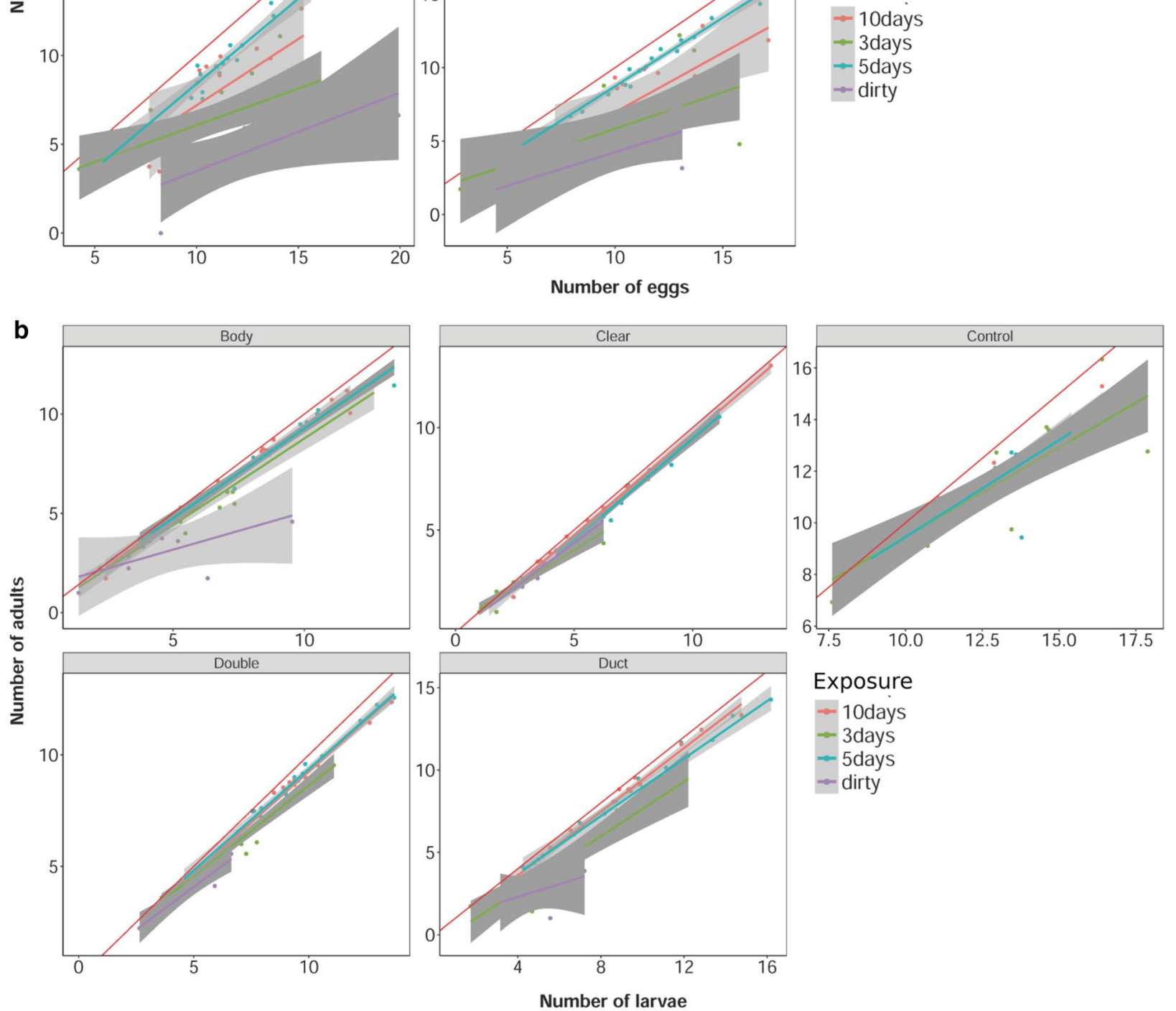

\section{- 10days \\ -3days \\ -5 days \\ - dirty}

Fig. 3 Visualisation of linear model $R^{2}$ data from hatch rate success of eggs picked up by tape types and subsequent adult emergence. a Visualised linear model of the hatch rate success of eggs picked up by different adhesive tape treatments. b Adult emergence from those successfully hatched 
Table 7 Linear model results of tape type and exposure vs hatch rate success of eggs from egg pick-up

\begin{tabular}{|c|c|c|c|c|c|c|}
\hline Tape type & Exposure (days) & $R^{2}$ & $\mathrm{~F}$ & $d f$ & Residual SE & P-value \\
\hline Control & 3 & 0.8926 & 125.6 & 14 & 1.233 & $2.24 \mathrm{E}-08^{* * *}$ \\
\hline BT & 3 & 0.5537 & 16.6 & 14 & 2.514 & $5.73 \mathrm{E}-04^{* * *}$ \\
\hline PT & 3 & 0.6197 & 25.4 & 14 & 1.683 & $1.79 \mathrm{E}-04^{* * *}$ \\
\hline$C T$ & 3 & 0.4160 & 11.7 & 14 & 2.604 & $4.16 \mathrm{E}-03^{* *}$ \\
\hline DT & 3 & 0.3552 & 9.3 & 14 & 3.021 & $8.76 \mathrm{E}-03^{* * *}$ \\
\hline Control & 5 & 0.7588 & 48.2 & 14 & 1.015 & $6.84 \mathrm{E}-06^{* * *}$ \\
\hline BT & 5 & 0.9509 & 291.2 & 14 & 0.649 & $9.14 \mathrm{E}-11^{* * *}$ \\
\hline PT & 5 & 0.9565 & 331.1 & 14 & 0.408 & $3.86 \mathrm{E}-11^{* * *}$ \\
\hline CT & 5 & 0.9156 & 163.7 & 14 & 0.647 & $4.09 \mathrm{E}-09^{* * *}$ \\
\hline DT & 5 & 0.9793 & 711.8 & 14 & 0.463 & $2.10 \mathrm{E}-13^{* * *}$ \\
\hline Control & 10 & 0.8934 & 126.7 & 14 & 1.001 & $2.11 \mathrm{E}-08^{* * *}$ \\
\hline BT & 10 & 0.5921 & 22.8 & 14 & 1.662 & $2.98 \mathrm{E}-04^{* * *}$ \\
\hline PT & 10 & 0.4102 & 11.4 & 14 & 2.508 & $4.49 \mathrm{E}-03^{* *}$ \\
\hline CT & 10 & 0.3118 & 7.8 & 14 & 2.062 & $1.44 \mathrm{E}-02^{*}$ \\
\hline DT & 10 & 0.3967 & 10.9 & 14 & 2.047 & $5.30 \mathrm{E}-03^{* * *}$ \\
\hline BT (Dirty) & 5 & 0.5239 & 8.7 & 6 & 2.112 & $2.56 \mathrm{E}-02^{*}$ \\
\hline PT (Dirty) & 5 & 0.7902 & 27.4 & 6 & 1.063 & $1.95 \mathrm{E}-03^{* *}$ \\
\hline CT (Dirty) & 5 & 0.4160 & 6.0 & 6 & 2.728 & $5.00 \mathrm{E}-02$ \\
\hline DT (Dirty) & 5 & 0.3870 & 5.4 & 6 & 2.227 & $5.88 \mathrm{E}-02$ \\
\hline
\end{tabular}

${ }^{*} \mathrm{P}<0.05,{ }^{* * P}<0.01,{ }^{* * *} \mathrm{P}<0.001$

Abbreviations: df, degrees of freedom; $\mathrm{SE}$, standard error

Table 8 Linear model results of tape type and exposure vs adult emergence success from hatched larvae

\begin{tabular}{|c|c|c|c|c|c|c|}
\hline Tape type & Exposure (days) & $R^{2}$ & $\mathrm{~F}$ & $d f$ & Residual SE & P-value \\
\hline Control & 3 & 0.7052 & 36.9 & 14 & 1.528 & $2.87 \mathrm{E}-05^{* * *}$ \\
\hline BT & 3 & 0.9493 & 282.0 & 14 & 0.596 & $1.13 \mathrm{E}-10^{* * *}$ \\
\hline PT & 3 & 0.9436 & 252.1 & 14 & 0.417 & $2.39 \mathrm{E}-10^{* * *}$ \\
\hline$C T$ & 3 & 0.9549 & 318.6 & 14 & 0.429 & $4.99 \mathrm{E}-11^{* * *}$ \\
\hline DT & 3 & 0.7707 & 51.4 & 14 & 1.389 & $4.78 \mathrm{E}-06^{* * *}$ \\
\hline Control & 5 & 0.7629 & 49.3 & 14 & 0.992 & $6.04 \mathrm{E}-06^{* * *}$ \\
\hline BT & 5 & 0.9765 & 624.9 & 14 & 0.427 & $5.13 \mathrm{E}-13^{* * *}$ \\
\hline PT & 5 & 0.9764 & 622.1 & 14 & 0.270 & $5.29 \mathrm{E}-13^{* * *}$ \\
\hline$C T$ & 5 & 0.9734 & 550.1 & 14 & 0.355 & $1.23 \mathrm{E}-12^{* * *}$ \\
\hline DT & 5 & 0.9436 & 251.8 & 14 & 0.699 & $2.41 \mathrm{E}-10^{* * *}$ \\
\hline Control & 10 & 0.9564 & 330.3 & 14 & 0.502 & $3.92 \mathrm{E}-11^{* * *}$ \\
\hline BT & 10 & 0.9802 & 744.4 & 14 & 0.413 & $1.54 \mathrm{E}-13^{* * *}$ \\
\hline PT & 10 & 0.9939 & 2432.0 & 14 & 0.209 & $2.00 \mathrm{E}-16^{* * *}$ \\
\hline $\mathrm{CT}$ & 10 & 0.9941 & 2518.0 & 14 & 0.232 & $2.00 \mathrm{E}-16^{* * *}$ \\
\hline DT & 10 & 0.9823 & 831.2 & 14 & 0.415 & $7.22 \mathrm{E}-14^{* * *}$ \\
\hline BT (Dirty) & 5 & 0.2725 & 3.6 & 6 & 2.005 & $1.06 \mathrm{E}-01$ \\
\hline PT (Dirty) & 5 & 0.9797 & 338.9 & 6 & 0.254 & $1.66 \mathrm{E}-06^{* * *}$ \\
\hline CT (Dirty) & 5 & 0.9671 & 206.6 & 6 & 0.391 & $7.10 \mathrm{E}-06^{* * *}$ \\
\hline DT (Dirty) & 5 & 0.4051 & 5.8 & 6 & 1.433 & $5.32 \mathrm{E}-02$ \\
\hline
\end{tabular}




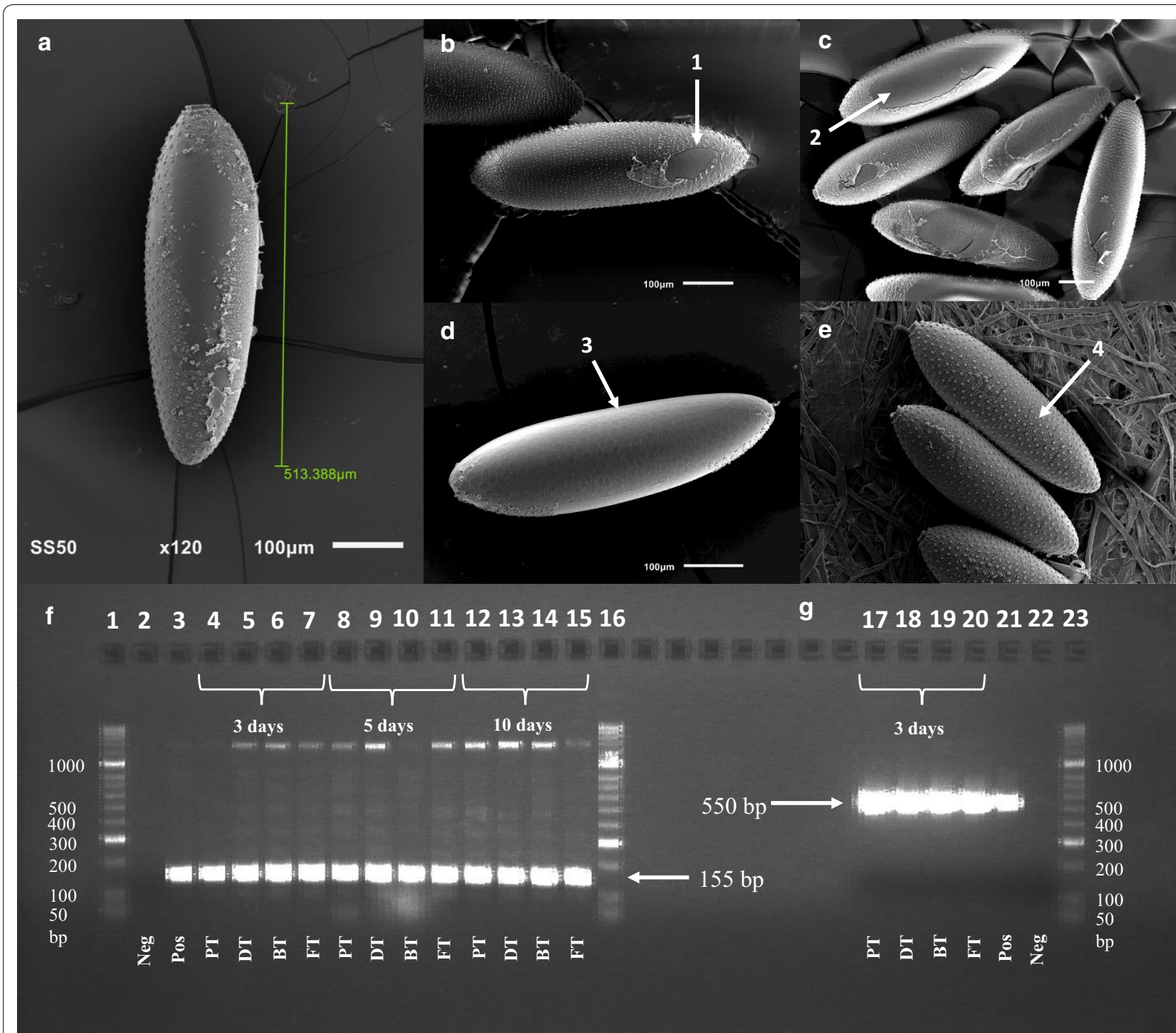

Fig. 4 Visualisation of DNA amplification and egg damage caused by egg removal. PCR amplification of Ae. aegypti using species-specific markers and visualisation of tape damage to the egg surface under SEM. a-e SEM micrographs of Ae. aegypti mosquito eggs. a Example of egg size, dorsal view, lifted from filter paper. b Dorsal view on BT (1, damage to chorion). c Dorsal view on DT (2, damage to chorion). d Dorsal view on FT (3, total removal of chorionic layer). e Ventral view, controls on filter paper (4, chorion intact). Gel electrophoresis results of PCR of eggs from car tyres using primers of Higa et al. [50] (f) and those of Das et al. [49] (g)

Therefore, understanding the viability of eggs after taping for downstream processing, such as rearing and identification, is essential. Additionally, the use of such tapes to sample dirty tyres in the field could result in unpredictable variance in hatch rate success when using a rearing approach for species identification. Therefore, we do not discourage but suggest caution when using this approach until field validation of this method is undertaken.

\section{Adhesive quality effect on egg pick-up}

From the data, we can infer that all tape types were able to pick up mosquito eggs from the surface of tyres with differing levels of efficiency. The tapes with greater adhesive strength (BT, DT, CT) were able to remove most of the eggs from any given area consistently, whereas clear packaging tape (PT), with the lowest adhesion of all those tested, proved to be significantly more variable suggesting that adhesive quality of tape is important if a surveillance strategy requires 
accurate population census information, but less important if only ascertaining presence/absence.

\section{Rearing from collected eggs}

The data collected shows that if a larva hatches from an egg collected by adhesive tape then it is likely to make it to adulthood. The success of hatching from eggs is much more variable and has a lower explanatory power than the controls. This suggests a possible underlying effect caused by egg removal using tape and could be explained by damage to the egg cuticle observed using SEM. However, mean hatch rate success over 5 and 10 days of exposure was above $50 \%$ for the first submergence, therefore this method is still useful for surveillance despite the negative impact caused by the sampling method. If only a small number of eggs are recovered during sampling, then we would advise a cautioned use of the rearing method.

This experiment also included a test on a set of dirty tyres with 5 days of exposure. Results showed that dirty tyres resulted in a lower explanatory power of the number of larvae from the number of eggs when using different tapes. It is likely that this is the result of (i) contamination of the tested tyres by an unknown introduced pathogen at source, or (ii) damage to the egg structure resulting in infection vulnerability from the unclean surface, or a loss in the ability to retain internal humidity. Although these hypotheses are plausible explanations for our results, further work using soiled tyres would be required to assess this.

We suggest that if the only facilities available for egg identification is through the rearing of larvae to adult, a tape with lower adhesive qualities is preferable, but will likely come at a cost of the total percentage of eggs picked up in a given area. As previously mentioned, caution should be taken when sampling dirty tyres in the field, as our result suggest it could affect both pickup and hatch rate success.

In the instance where larval rearing is the preferred approach, our model showed that using egg number to explain larvae number, or larvae number to explain adult number, is highest (highest $R^{2}$ ) at 5 days. Therefore, larval rearing at 5 days from the date of sampling would be optimal. The experiments tested here are from a laboratory-based study only, during field application, eggs are likely to have been attached to the tyre surface for an unknown period producing an additional unpredictability factor when estimating hatch rate success in wild sampled populations. It would be interesting to test egg viability in combination with our methods based on actual shipping conditions (e.g. duration of the journey, predicted climate condition inside the containers, etc.) in order to develop a predictability model on the likelihood of emergent risk of AIMs.

\section{PCR-based identification}

Where larval/adult rearing is not practical, or a faster method of species identification is required, species genotyping is a viable alternative. We tested this method using egg loaded tape sections from each of the treatments to observe whether amplification was possible after exposure to the tape surface. A targeted speciesspecific approach was chosen as a preferable method to eliminate amplification from potential sources of contamination from the surface of the tyres. We would recommend that similar tests are undertaken during any field trials that expand this sampling method. However, there have been only several targeted species-specific assays produced for regions that are inflicted with a unique collection of problematic species [52, 53, 59, 6973]. Alternative methods of species identification using eDNA, or the application of metabarcoding could prove to be a valuable alternative to species specific assays but will require further development.

\section{Conclusions}

This study has shown that a method of screening used tyres for mosquito eggs with sticky tape could prove to be a useful tool in the surveillance of AIMs that pose a serious threat to human health. Despite the global threat, there is currently no surveillance technique that screens for the presence of AIM eggs as a primary introduction route. Identification at this point is important as AIMs have proven to be biologically adaptive to new conditions and are successfully invasive in many areas around the world $[19,20]$. This study has demonstrated that low-cost adhesive tape can be used to detect the eggs of Ae. aegypti from tyres and could also be used for other species, notably Ae. albopictus. The benefits of this are three-fold. First, and most importantly, suspected eggs on the tape can be visualized with a hand-held lens which means fast screening of cargo can be achieved. This could result in a shipment being held or tracked to the onward destination where targeted control methods could be deployed if eggs are confirmed to be from AIMs. We have provided a flow chart to describe how the procedural process for such screening processes could take place (Fig. 5). Additionally, this method could be used to survey any location where tyre sampling is required (i.e. tyre yards, waste piles). Secondly, the ability to hatch and rear eggs through larvae to adults is possible although further field studies will be required to understand how environmental variables could affects factors such as egg 


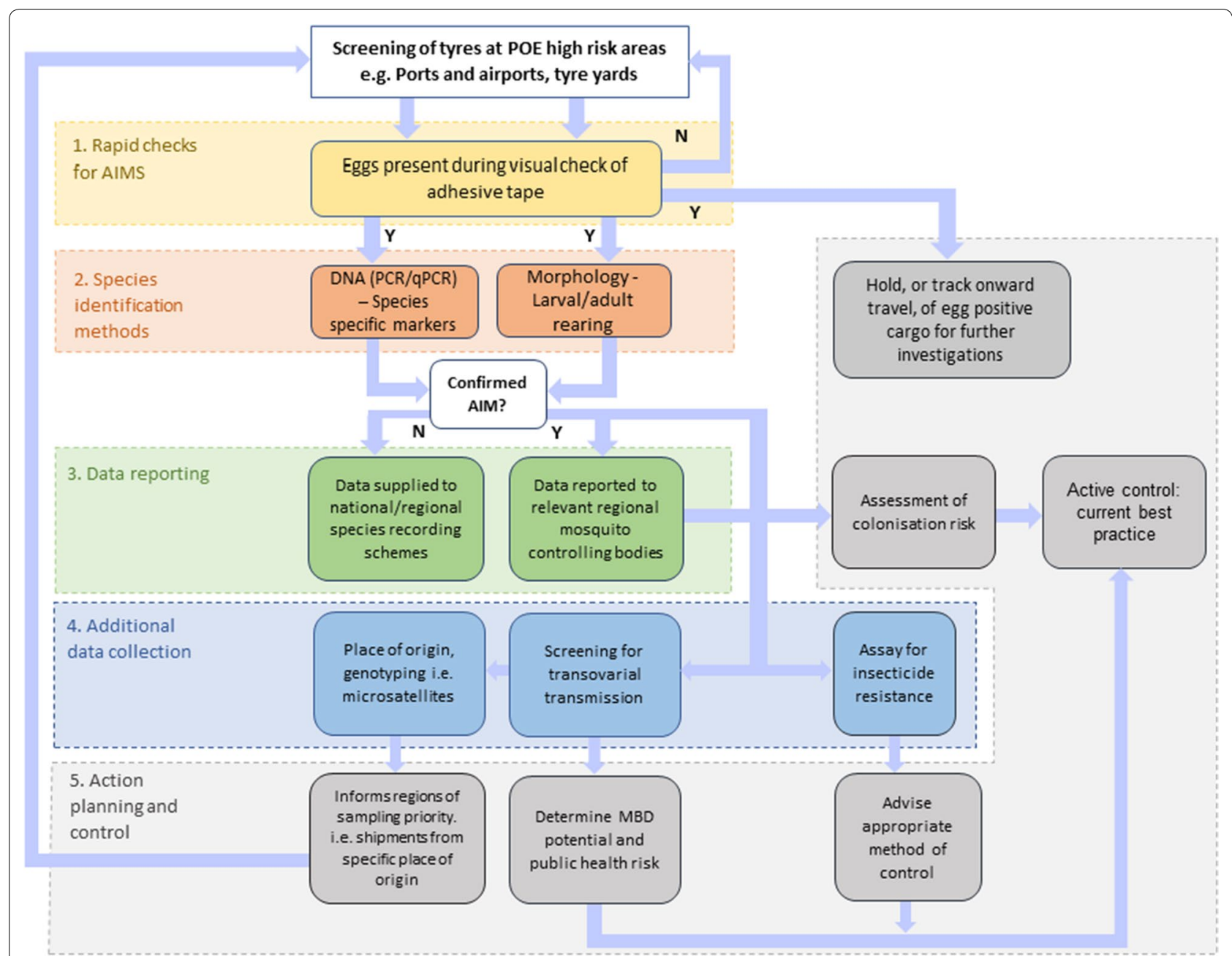

Fig. 5 Flow diagram of a recommended procedural process for screening car tyres with adhesive tape. Abbreviations: POE, point of entry; AIM, Aedes invasive mosquito; MBD, mosquito-borne disease

mortality. Larval and adult rearing allows for morphological identification and additional downstream investigations (e.g. screening for insecticide susceptibility and transovarial transmission of diseases) [74]. Insecticide resistance screening is important given the worldwide spread of insecticide resistance and because AIMs can be imported from any country where they are present, irrespective of disease presence or absence. Lastly, the tapes tested showed no inhibition of PCR amplification, therefore, additional information can be gained from the DNA of any samples collected (e.g. population genetics). Due to the low cost and potentially high levels of efficiency, further development of this method could allow it to be deployed internationally, acting as an early warning system for new introductions. However, additional validation of this technique in the field would be advantageous to quantify the effects of sampling soiled tyres. We are currently devising a convenient method of applying tape to the tyre surface to produce a standardised methodology.

\section{Abbreviations}

AIM(s): Aedes invasive mosquito(es); SEM: scanning electron microscopy; DENV: dengue fever; CHIKV: chikungunya virus; ZIKV: Zika virus; SC: serosal cuticle; PCR: polymerase chain reaction; DT: duct tape; BT: body tape; FT: double sided floor tape; PT: clear packing tape; PHA: port health authorities.

\section{Acknowledgements}

We would like to thank Merseyside Port Health Authority (PHA) for involvement in developing the concept, Jasmin Kean for assisting in mosquito rearing. Thanks also to Carl Barker, Ashley Lyons and Elizabeth Sullivan, for suggestions on statistical approaches. Michelle Williams from the Liverpool School of Tropical Medicine kindly supplied the Ae. aegypti (New Orleans strain) for the study. Finally, we are grateful to Andre Hunt from Heysham and Glasson PHA for suggestions on practicality on the field. The work of Clare Strode was done under the frame of AIM-COST Action CA17108.

\section{Authors' contributions}

TD, primary author, was involved in conceptual development, statistical analysis, project design and implementation of laboratory work. DG contributed 
significantly to laboratory work and project design. SB contributed to statistical analysis and writing of the paper. CS secured funding for the project and was involved in conceptual development, project design and writing of the paper. All authors read and approved the final manuscript.

\section{Funding}

The work was funded by Edge Hill University's 'Research Investment Fund' (RDSTRO15).

\section{Availability of data and materials}

All data generated or analysed during this study are included in this published article.

\section{Ethics approval and consent to participate}

Not applicable.

\section{Consent for publication}

Not applicable.

\section{Competing interests}

The authors declare that they have no competing interests.

Received: 21 June 2019 Accepted: 3 February 2020

Published online: 19 February 2020

\section{References}

1. Bhatt $S$, Gething PW, Brady OJ, Messina JP, Farlow AW, Moyes $C L$, et al. The global distribution and burden of dengue. Nature. 2013;496:504-7.

2. Carabali M, Hernandez LM, Arauz MJ, Villar LA, Ridde V. Why are people with dengue dying? A scoping review of determinants for dengue mortality. BMC Infect. 2015;15:301.

3. Brady OJ, Gething PW, Bhatt S, Messina JP, Brownstein JS, Hoen AG, et al. Refining the global spatial limits of dengue virus transmission by evidence-based consensus. PLoS Negl Trop Dis. 2012;6(8):e1760.

4. European Centre for Disease Prevention and Control. Rapid risk assessment: Zika virus epidemic in the Americas: potential association with microcephaly and Guillain-Barré syndrome-10 December 2015. Stockholm: ECDC; 2015. p. 1-14.

5. Mlakar J, Korva M, Tul N, Popović M, Poljšak-Prijatelj M, Mraz J, et al. Zika virus associated with microcephaly. N Engl J Med. 2016;374:951-8.

6. Calvet G, Aguiar RS, Melo ASO, Sampaio SA, de Filippis I, Fabri A, et al. Detection and sequencing of Zika virus from amniotic fluid of fetuses with microcephaly in Brazil: a case study. Lancet Infect Dis. 2016;16:653-60.

7. Musso D, Nilles EJ, Cao-Lormeau VM. Rapid spread of emerging Zika virus in the Pacific area. Clin Microbiol Infect. 2014;20:0596.

8. Gatherer D, Kohl A. Zika virus: a previously slow pandemic spreads rapidly through the Americas. J Gen Virol. 2016;97:269-73.

9. Roth A, Mercier A, Lepers C, Hoy D, Duituturaga S, Benyon E, et al. Concurrent outbreaks of dengue, chikungunya and Zika virus infections - an unprecedented epidemic wave of mosquito-borne viruses in the Pacific 2012-2014. Euro Surveill. 2014;19:20929.

10. Kindhauser MK, Allen T, FrankV, Santhana S, Dye C. Zika: the origin and spread of a mosquito-borne virus. Bull World Health Organ. 2016;94:675-86C

11. Grubaugh ND, Faria NR, Andersen KG, Pybus OG. Genomic insights into Zika virus emergence and spread. Cell. 2018;172:1160-2.

12. Ngoagouni C, Kamgang B, Nakouné E, Paupy C, Kazanji M. Invasion of Aedes albopictus (Diptera: Culicidae) into central Africa: what consequences for emerging diseases? Parasites Vectors. 2015;8:191.

13. Russell BM, Kay BH, Shipton W. Survival of Aedes aegypti (Diptera: Culicidae) eggs in surface and subterranean breeding sites during the northern Queensland dry season. J Med Entomol. 2001;38:441-5.

14. Lima A, Lovin DD, Hickner PV, Severson DW. Evidence for an overwintering population of Aedes aegypti in Capitol Hill Neighborhood, Washington, DC. Am J Trop Med Hyg. 2016;94:231-5.

15. Brown JE, Scholte EJ, Dik M, den Hartog W, Beeuwkes J, Powell JR. Aedes aegypti mosquitoes imported into the Netherlands, 2010. Emerg Infect Dis. 2011;17:2335-7.
16. Demeulemeester J, Deblauwe I, De Witte JC, Jansen F, Hendy A, Madder M. First interception of Aedes (Stegomyia) albopictus in lucky bamboo shipments in Belgium. J Eur Mosq Control Assoc. 2014;32:14-6.

17. Hofhuis A, Reimerink J, Reusken C, Scholte EJ, de Boer A, Takken W, et al. The hidden passenger of lucky bamboo: do imported Aedes albopictus mosquitoes cause dengue virus transmission in the Netherlands? Vector Borne Zoonotic Dis. 2009;9:217-20.

18. Jupp PG, Kemp A. Aedes albopictus and other mosquitoes imported in tires into Durban, South Africa. J Am Mosq Control Assoc. 1992;8:321-2.

19. Lounibos PL. Invasion by insect vectors of human disease. Annu Rev Entomol. 2002;47:233-66.

20. Louniboss PL, Kramer LD. Invasiveness of Aedes aegypti and Aedes albopictus and vectorial capacity for chikungunya virus. J Infect Dis. 2016;214(Suppl. 5):453-8.

21. Christophers RS. Aedes aegypti (L.) The yellow fever mosquito. Cambridge: Cambridge University Press; 1960.

22. Beckel WE. Investigations of permiability, diapause, and hatching in the eggs of the mosquito Aedes hexodontus Dyar. Can J Zool. 1958;36:541-54.

23. Rezende GL, Martins AJ, Gentile C, Farnesi LC, Pelajo-Machado M, Peixoto AA, et al. Embryonic desiccation resistance in Aedes aegypti: presumptive role of the chitinized serosal cuticle. BMC Dev Biol. 2008;8:82.

24. Clements A. The biology of mosquitoes: development, nutrition and reproduction. Wallingford: CABI Publishing; 1992.

25. Padmaja K, Sundara Rajulu G. Chemical nature of the chorionic pad of the egg of Aedes aegypti. Mosq News. 1981;41:674-6.

26. Bosworth AB, Meola SM, Thompson M, Olson JK. Chorionic morphology of eggs of the Psorophora confinnis compex in the United States. II. Pre- and postdeposition studies of Psorophora columbiae (Dyar and Knab) eggs. J Am Mosq Control Assoc. 1998;14:46-57.

27. Powell PR, Tabachnick WJ. History of domestication and spread of Aedes aegypti-a review. Mem Inst Oswaldo Cruz. 2013;108(Suppl. 1):11-7.

28. Kraemer MUG, Sinka ME, Duda KA, Mylne AQN, Shearer FM, Barker CM, et al. The global distribution of the arbovirus vectors Aedes aegypti and Ae. albopictus. eLife. 2015;4:e08347.

29. Tomasello D, Schlagenhauf P. Chikungunya and dengue autochthonous cases in Europe, 2007-2012. Travel Med Infect Dis. 2013;11:274-84.

30. Dallimore T, Hunter T, Medlock JM, Vaux AGC, Harbach RE, Strode C. Discovery of a single male Aedes aegypti (L.) in Merseyside, England. Parasites Vectors. 2017;10:309.

31. Goubert C, Henri H, Minard G, Valiente Moro C, Mavingui P, Vieira C, et al. High-throughput sequencing of transposable element insertions suggests adaptive evolution of the invasive Asian tiger mosquito towards temperate environments. Mol Ecol. 2017;26:3968-81.

32. Trpis $M$, Hausermann W. Dispersal and other population parameters of Aedes aegypti in an African village and their possible significance in epidemiology of vector-borne diseases. Am J Trop Med Hyg. 1986;35:1263-79.

33. Harrington LC, Scott TW, Lerdthusnee K, Coleman RC, Costero A, Clark GG, et al. Dispersal of the dengue vector Aedes aegypti within and between rural communities. Am J Trop Med Hyg. 2005;72:209-20.

34. Maciel-de-Freitas R, Torres Codeço C, Lourenço-de-Oliveira R, et al. Daily survival rates and dispersal of Aedes aegypti females in Rio de Janeiro, Brazil. Am J Trop Med Hyg. 2007;76:659-65.

35. Eritja R, Palmer JRB, Roiz D, Sanpera-Calbet I, Frederic B. Direct evidence of adult Aedes albopictus dispersal by car. Sci Rep. 2017;7:14399.

36. Medlock JM, Vaux AG, Cull B, Schaffner F, Gillingham E, Pfluger V, et al. Detection of the invasive mosquito species Aedes albopictus in southern England. Lancet Infect Dis. 2017;17:P140.

37. Becker N, Geier M, Balczun C, Bradersen U, Huber K, Kiel E, et al. Repeated introduction of Aedes albopictus into Germany, July to October 2012. Parasitol Res. 2013;112:1787-90.

38. Reiter P, Sprenger D. The used tire trade: a mechanism for the worldwide dispersal of container breeding mosquitoes. J Am Mosq Control Assoc. 1987;3:494-501.

39. Reiter P. Aedes albopictus and the world trade in used tires, 1988-1995: the shape of things to come? J Am Mosq Control Assoc. 1998;14:83-94.

40. Vaux AGC, Medlock JM. Current status of invasive mosquito surveillance in the UK. Parasites Vectors. 2015;8:351.

41. Eropean Centre for Disease Prevention and Control. Guidelines for the surveillance of invasive mosquitoes in Europe. Stockholm: ECDC; 2012.

42. Schaffner E, Angel G, Geoffroy B, Hervy J-P, Rhaiem A, Brunhes J. Les moustiques d'Europe: logiciel d'identification et d'enseignement. The 
mosquitoes of Europe: an identification and training programme. Paris: IRD Éditions; 2001.

43. Schaffner F, Bellini R, Dusan P, Scholte E-J, Zeller H, Marrama Rakotoarivony $L$. Development of guidelines for the surveillance of invasive mosquitoes in Europe. Parasites Vectors. 2013;6:209.

44. Porse CC, Kramer V, Yoshimizu MH, Metzger M, Hu R, Padgett K, et al. Public health response to Aedes aegypti and Ae. albopictus mosquitoes invading California, USA. Emerg Infect Dis. 2015;21:1827-9.

45. Doosti S, Yaghoobi-Ershadi MR, Schaffner F, Moosa-Kazemi SH, Akbarzadeh K, Gooya MM, et al. Mosquito surveillance and the first record of the invasive mosquito species Aedes (Stegomyia) albopictus (Skuse) (Diptera: Culicidae) in southern Iran. Iran J Public Health. 2016;45:1064-73.

46. Kumar K, Sharma AK, Sarkar M, Chauhan A, Sharma R. Surveillance of Aedes aegypti (L.) mosquitoes in Mumbai International Seaport (India) to monitor potential global health risks. J Insects. 2014;2014:951015.

47. Silver JB. Mosquito ecology: field sampling methods. 3rd ed. Heidelberg: Springer, Netherlands; 2008.

48. Vazquez-Prokopec GM, Chaves LF, Ritchie SA, Davis J, Kitron U. Unforeseen costs of cutting mosquito surveillance budgets. PLoS Negl Trop Dis. 2010:4:e858.

49. Scholte E, Den Hartog W, Dik M, Schoelitsz B, Brooks M, Schaffner F, et al. Introduction and control of three invasive mosquito species in the Netherlands, July-October 2010. Euro Surveill. 2010;15:19710.

50. Zheng M-L, Zhang D-J, Damiens DD, Lees RS, Gilles JRL. Standard operating procedures for standardized mass rearing of the dengue and chikungunya vectors Aedes aegypti and Aedes albopictus (Diptera: Culicidae)—II_egg storage and hatching. Parasites Vectors. 2015;8:348.

51. Ross PA, Endersby-Harshman NM, Hoffmann AA. A comprehensive assessment of inbreeding and laboratory adaptation in Aedes aegypti mosquitoes. Evol Appl. 2019;12:572-86.

52. Das B, Swain S, Patra A, Das M, Tripathy HK, Mohapatra N, et al. Development and evaluation of a single-step multiplex PCR to differentiate the aquatic stages of morphologically similar Aedes (subgenus: Stegomyia) species. Trop Med Int Health. 2012;17:235-43.

53. Higa Y, Toma T, Tsuda Y, Miyagi I. A multiplex PCR-based molecular identification of five morphologically related, medically important subgenus Stegomyia mosquitoes from the genus Aedes (Diptera: Culicidae) found in the Ryukyu Archipelago, Japan. Jpn J Infect Dis. 2010;63:312-6.

54. Farnesi LC, Menna-Barreto RFS, Martins AJ, Valle D, Rezende GL. Physical features and chitin content of eggs from the mosquito vectors Aedes aegypti, Anopheles aquasalis and Culex quinquefasciatus: connection with distinct levels of resistance to desiccation. J Insect Physiol. 2015:83:43-52.

55. Noireau F, Abad-Franch F, Valente SAS, Dias-Lima A, Lopes CM, Cunha V, et al. Trapping Triatominae in silvatic habitats. Mem Inst Oswaldo Cruz, Rio de Janeiro. 2002;97:61-3.

56. Carroll MJ, Dennis P, Pearce-Higgins JW, Thomas CD, et al. Maintaining northern peatland ecosystems in a changing climate: effects of soil moisture, drainage and drain blocking on craneflies. Glob Change Biol. 2011;17:2991-3001.

57. Schaffner F, Kaufmann C, Pflüger V, Mathis A. Rapid protein profiling facilitates surveillance of invasive mosquito species. Parasites Vectors. 2014;7:142.

58. Suman DS, Shrivastava AR, Pant SC, Parashar BD. Differentiation of Aedes aegypti and Aedes albopictus (Diptera: Culicidae) with egg surface morphology and morphometrics using scanning electron microscopy. Arthropod Struct Dev. 2011;40:479-83.

59. Beebe NW, Whelan PI, Van Den Hurk AF, Ritchie SA, Corcoran S, Cooper $\mathrm{RD}$. A polymerase chain reaction-based diagnostic to identify larvae and eggs of container mosquito species from the Australian region. J Med Entomol. 2007:44:376-80.

60. Werblow A, Flechl E, Klimpel S, Zittra C, Lebl K, Kieser K, et al. Direct PCR of indigenous and invasive mosquito species: a time- and cost-effective technique of mosquito barcoding. Med Vet Entomol. 2016;30:8-13.

61. Zamora-Delgado J, Carlos Castaño J, Hoyos-López R. DNA barcode sequences used to identify Aedes (Stegomyia) albopictus (Diptera: Culicidae) in La Tebaida (Quindío, Colombia). Rev Colomb Entomol. 2015:41:212-7.

62. Schneider J, Valentini A, Dejean T, Montarsi F, Taberlet P, Glaizot O, et al. Detection of invasive mosquito vectors using environmental DNA (eDNA) from water samples. PLoS ONE. 2016;11:e0162493.

63. Morlan HB, Hayes RO, Schoof HF. Methods for mass rearing of Aedes aegypti (L.). Public Health Rep. 1963;78:711-9.

64. Munstermann LE, Wasmuth LM. Aedes aegypti. In: Singh P, Moore RF, editors. Handbook of insect rearing. Amsterdam: Elsevier; 1985. p. 7-13.

65. Munstermann LE. Care and maintenance of Aedes mosquito colonies. In: Crampton JM, Beard CB, Louis C, editors. The molecular biology of insect disease vectors. A methods manual. Dordrecht: Springer, Netherlands; 1997. p. 13-20.

66. Kutsuna S, Kato Y, Moi ML, Kotaki A, Ota M, Shinohara K, et al. Autochthonous dengue fever, Tokyo, Japan, 2014. Emerg Infect Dis. 2015;21:517-20.

67. Huang X, Williams G, Clements ACA, Hu W. Imported dengue cases, weather variation and autochthonous dengue incidence in Cairns, Australia. PLOS ONE. 2013;8:1-7.

68. Rey JR. Dengue in Florida (USA). Insects. 2014;5:991-1000.

69. Gould EA, Gallian P, De Lamballerie X, Charrel RN. First cases of autochthonous dengue fever and chikungunya fever in France: from bad dream to reality! Clin Microbiol Infect. 2010;16:1702-4.

70. Venturi G, Di Luca M, Fortuna C, Elena Remoli M, Riccardo F, Severini F, et al. Detection of a chikungunya outbreak in central Italy, August to September 2017. Euro Surveill. 2017;22:1700646.

71. Cook S, Diallo M, Sall AA, Cooper A, Holmes EC. Mitochondrial markers for molecular identification of Aedes mosquitoes (Diptera: Culicidae) involved in transmission of arboviral disease in West Africa. Evol J Med Entomol. 2005:42:19-28.

72. Hill LA, Davis JB, Hapgood G, Whelan PI, Smith GA, Ritchie SA, et al. Rapid identification of Aedes albopictus, Aedes scutellaris, and Aedes aegypti life stages using real-time polymerase chain reaction assays. Am J Trop Med Hyg. 2008;79:866-75.

73. Van De Vossenberg BTLH, Ibáñez-Justicia A, Metz-Verschure E, Van Veen EJ, Bruil-Dieters ML, Scholte EJ. Real-time PCR tests in Dutch exotic mosquito surveys; implementation of Aedes aegypti and Aedes albopictus identification tests, and the development of tests for the identification of Aedes atropalpus and Aedes japonicus japonicus (Diptera: Culicidae). J Med Entomol. 2015;52:336-50.

74. Da Costa CF, Dos Passos RA, Lima JBP, Roque RA, De Souza Sampaio V, Campolina TB, et al. Transovarial transmission of DENV in Aedes aegypti in the Amazon basin: a local model of xenomonitoring. Parasites Vectors. 2017;10:249.

\section{Publisher's Note}

Springer Nature remains neutral with regard to jurisdictional claims in published maps and institutional affiliations.

Ready to submit your research? Choose BMC and benefit from:

- fast, convenient online submission

- thorough peer review by experienced researchers in your field

- rapid publication on acceptance

- support for research data, including large and complex data types

- gold Open Access which fosters wider collaboration and increased citations

- maximum visibility for your research: over 100M website views per year

At BMC, research is always in progress.

Learn more biomedcentral.com/submissions 